\title{
The effect of alogliptin and pioglitazone combination therapy on various aspects of $\beta$-cell function in patients with recent-onset type 2 diabetes
}

\author{
Daniël H Van Raalte ${ }^{*}$, Renate E van Genugten ${ }^{*}$, Björn Eliasson", \\ Diane L Möller-Goede, Andrea Mari' ${ }^{2}$, Andrea Tura², Craig Wilson ${ }^{3}$, Penny Fleck ${ }^{3}$, \\ Marja R Taskinen ${ }^{4}$, Ulf Smith ${ }^{1}$ and Michaela Diamant \\ Diabetes Center, VU University Medical Center, De Boelelaan 1117, 1081 HV Amsterdam, The Netherlands, \\ 'Lundberg Laboratory for Diabetes Research, Department of Medicine, Gothenburg, Sweden, ${ }^{2}$ Institute of \\ Biomedical Engineering, National Research Council, Padova, Italy, ${ }^{3}$ Takeda Global Research and Development \\ Center (Europe) Ltd, London, UK and ${ }^{4}$ Biomedicum, Helsinki University Central Hospital and University of Helsinki, \\ Helsinki, Finland \\ *(D H Van Raalte and R E van Genugten contributed equally to this work)
}

\author{
Correspondence \\ should be addressed \\ to D H Van Raalte \\ Email \\ d.vanraalte@vumc.nl
}

\begin{abstract}
Objective: Type 2 diabetes mellitus (T2DM) management requires continuous treatment intensification due to progressive decline in $\beta$-cell function in insulin resistant individuals. Initial combination therapy of a dipeptidyl peptidase (DPP)-4 inhibitor with a thiazolidinedione (TZD) may be rational. We assessed the effects of the DPP4 inhibitor alogliptin (ALO) combined with the TZD pioglitazone (PIO), vs ALO monotherapy or placebo (PBO), on $\beta$-cell function and glycemic control in T2DM.

Material and methods: A 16-week, two-center, randomized, double-blind, PBO-controlled, parallel-arm intervention study in 71 patients with well-controlled T2DM (age $59.1 \pm 6.3$ years; A1C 6.7 $\pm 0.1 \%$ ) treated with metformin, sulfonylurea, or glinide monotherapy was conducted. Patients were treated with combined ALO $25 \mathrm{mg}$ and PIO $30 \mathrm{mg}$ daily or ALO $25 \mathrm{mg}$ daily monotherapy or PBO. Main outcome measures included change in A1C and fasting plasma glucose (FPG) from baseline to week 16. In addition, change in $\beta$-cell function parameters obtained from standardized meal tests at baseline and at week 16 was measured.

Results: ALO/PIO and ALO decreased A1C from baseline by $0.9 \pm 0.1$ and $0.4 \pm 0.2 \%$ respectively (both $P<0.001$ vs $\mathrm{PBO}$ ). FPG was decreased to a greater extent by ALO/PIO compared with ALO monotherapy $(P<0.01)$. ALO/PIO treatment improved $\beta$-cell glucose sensitivity (vs PBO; $P<0.001$ ) and fasting secretory tone (vs PBO; $P=0.001$ ), while ALO monotherapy did not change $\beta$-cell function parameters. All treatments were well tolerated.

Conclusion: Short-term treatment with ALO/PIO or ALO improved glycemic control in well-controlled T2DM patients, but only combined ALO/PIO improved $\beta$-cell function. These data support that initial combination therapy with a DPP4 inhibitor and TZD to address multiple core defects in T2DM may be a sensible approach.

\section{Introduction}

Type 2 diabetes mellitus (T2DM) is characterized by $\beta$-cell dysfunction against a background of reduced insulin sensitivity $(1,2)$. The optimal management for hyperglycemia in T2DM patients is still under debate. Despite the availability of novel therapeutic agents, optimal glycemic control is achieved only in a minority
(C) 2014 European Society of Endocrinology Printed in Great Britain
Published by Bioscientifica Ltd. 
of patients and is often of short duration due to progressive decline in $\beta$-cell function (3). This may in part be due to the currently advocated treatment paradigm, which is characterized by a stepwise approach (4). After initiation of lifestyle interventions and metformin treatment, another anti-hyperglycemic agent, classically sulfonylurea, or basal insulin is added (1), although in the last EASD/ADA statement recently developed drugs, i.e. the thiazolidinediones (TZDs), glucagon-like peptide-1 receptor agonists (GLP1RA) or dipeptidyl peptidase-4 (DPP4) inhibitors, are allowed. Despite this broadening of treatment options, the stepwise approach may be ineffective due to the fact that intensification is often delayed (5) and serial failures are frequently observed due to modest $\mathrm{A} 1 \mathrm{C}$ reductions following introduction of glucose-lowering therapies after metformin therapy (6). In addition, the current treatment strategy does not address the multiple core defects of T2DM at the same time, i.e. islet-cell dysfunction, insulin resistance, and impaired incretin action.

Another regimen that was proposed, but for which to date evidence is scarce, is to start aggressively, using initial combinations of different agents that address the core defects of T2DM at the same time $(1,5,7)$. In this regard, combination therapy with incretin-based therapies, i.e. either GLP1RA or DPP4 inhibitors, agents that were shown to improve $\alpha$ - and $\beta$-cell function in humans $(8,9)$, and insulin sensitizing agents, such as metformin or TZDs may have synergistic, more durable, and potentially disease-modifying effects. Beside their effects on islet cell function, DPP4 inhibitors are weight-neutral and their use is associated with low hypoglycemia rates (10). TZDs not only enhance hepatic and peripheral insulin sensitivity but were also shown to improve $\beta$-cell function (11). Indeed, TZDs uniquely were shown to durably lower A1C in several studies in T2DM for up to several years of treatment (1).

Previously, DPP4 inhibitor and TZD combined treatment improved glycemic control in T2DM, when used as add-on therapy $(12,13)$ or as initial combination therapy $(14,15)$. However, the initial effects of combined DPP4/TZD therapy on $\beta$-cell function in T2DM patients have currently not been studied. In this study, we investigated the effects of initial combination therapy with the DPP4 inhibitor alogliptin (ALO) (16) and the TZD pioglitazone (PIO) on model-derived parameters of $\beta$-cell function, obtained from standardized meal tests in T2DM patients, whose glycemic control was just off target on monotherapy with one single oral hypoglycemic agent (metformin, sulfonylurea, or glinide). The effects of initial combination therapy were compared with ALO monotherapy or placebo (PBO).

\section{Subjects and methods}

Recently, the main paper of this study has been published, which reported on the effects of study medication on postprandial triglyceride metabolism. Throughout this paper, we refer to that manuscript on several occasions (17).

\section{Patients}

Subjects were recruited from community hospital diabetes outpatient clinics and by newspaper advertisements. Seventy-one patients were enrolled (Fig. 1). Study participants were between 18 and 70 years old, had T2DM, and had not reached adequate glycemic control with diet and exercise or a stable dose of metformin, sulfonylurea, or glinide for more than 3 months before screening. Study medication was added-on to this ongoing monotherapy, which was continued during the study. Major entry criteria included a baseline A1C 6.5-9.0\% (48-75 mmol/mol), fasting plasma glucose (FPG) $<13.3 \mathrm{mmol} / \mathrm{l}$, and BMI $23-45 \mathrm{~kg} / \mathrm{m}^{2}$ (17). All nonexcluded medications should have been taken on a stable dose since at least 4 weeks before screening. The participants agreed to maintain their previous diet and exercise regimen during the full course of the study.

Major exclusion criteria included use of weightlowering drugs, glucocorticoids, lipid-lowering agents (other than statins or ezetimibe), or any investigational blood glucose lowering agent within the past 3 months. Furthermore, patients with a history of type 1 diabetes,

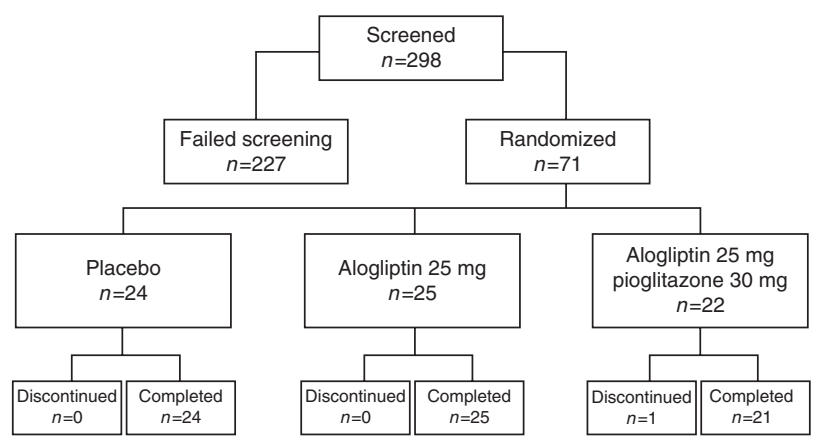

Figure 1

Patient disposition. 
hypertension, or allergies to ALO or PIO were excluded. The study protocol was approved by the ethics review board at each study site and was in accordance with the principles described in the declaration of Helsinki. All study participants gave their written informed consent before screening. The study is registered with ClinicalTrials.gov (NCT00655863).

\section{Study design}

This was a 16-week phase IIIB, two-center, randomized, double-blind, PBO-controlled, parallel-group trial comparing the effects of ALO alone, combination therapy with ALO and PIO, or PBO. The study was carried out between August 2007 and December 2009 in two study sites (university hospitals) in Sweden and The Netherlands.

Following the screening visit and confirmation of eligibility, patients were randomized (allocation by central office) within 14 days at baseline to one of three treatment groups in a 1:1:1 ratio to receive ALO $25 \mathrm{mg}$ daily, co-administration of ALO $25 \mathrm{mg}$ and PIO $30 \mathrm{mg}$ (ALO/PIO) daily, or PBO. Mean adherence during the study was similar for the PBO (96.1\%), ALO (97.8\%), and ALO/PIO groups (97.4\%). All participants, investigators performing measurements or examinations, or investigators assessing the outcomes were blinded to group assignment. The participants returned to the study site at weeks 4,8 , and 16 for study assessments. Patients were asked to fast overnight for $8 \mathrm{~h}$ and to abstain from alcohol ingestion for 3 days and from strenuous exercise for $24 \mathrm{~h}$ before the screening, baseline, and weeks 4,8 , and 16 visits.

\section{Standardized meal test}

At baseline and week 16, a standardized meal was given in the morning. No study medication was given before the test meal at baseline. Study medication was taken with $200 \mathrm{ml}$ water $30 \mathrm{~min}$ before the meal at week 16 . The standardized test meal, which contained $\sim 919 \mathrm{kcal}$ with $14 \%$ protein, $49 \%$ fat, and 36\% carbohydrates, was consumed within $10 \mathrm{~min}$. Blood samples were drawn from a catheter placed in the antecubital vein at 15 and $5 \mathrm{~min}$ before starting the meal, and $0.25,0.5,1,2,3,4,5,6,7$, and $8 \mathrm{~h}$ after the meal. Subjects were allowed to drink only water until the final blood sample had been collected. Glucose, insulin, and C-peptide samples were obtained at every time point of the standardized test meal. A1C was obtained during the study visits at baseline, week 8 , and week 16 .

\section{Analytical determinations}

Plasma glucose, insulin, and C-peptide were analyzed at the Department of Clinical Chemistry, Sahlgrenska University Hospital, Göteborg, Sweden. GLP1 and glucagon were analyzed at the Department of Biomedical Sciences, The Panum Institute, University of Copenhagen, Denmark.

\section{Data analyses}

Absolute area under the 8-h postprandial curves (AUC) for glucose, insulin, and C-peptide curves was determined by using the trapezoidal rule. Homeostatic model assessment of insulin sensitivity (HOMA-S) was calculated for fasting insulin sensitivity (18). Oral glucose insulin sensitivity (OGIS) as a measure for postprandial insulin sensitivity was calculated (19).

\section{$\beta$-cell function during the standardized meal test}

Pancreatic $\beta$-cell function was assessed with a model that describes the relationship between insulin secretion and glucose concentration, which has been described in detail previously $(20,21)$. The model expresses insulin secretion (in $\mathrm{pmol} / \mathrm{min}$ per $\mathrm{m}^{2}$ of body surface area) as the sum of two components. The first component describes the doseresponse relation between insulin secretion and glucose concentrations during the meal test. Three parameters are obtained from this dose-response relation. The first is the sensitivity of the $\beta$-cell to changes in plasma glucose levels, called glucose sensitivity. It is derived from the mean slope of the dose-response curve. Second, the fasting secretory tone is calculated from the dose-response curve. This represents fasting insulin secretion rates (ISR) at a fixed glucose concentration of $8 \mathrm{mM}$ (approximately the mean fasting glucose concentration in the groups). The third parameter is a potentiation factor, which may account for several potentiating signals to the $\beta$-cell (e.g. nonglucose metabolites, gastro-intestinal hormones, and neural factors) or amplifying pathways within the $\beta$-cell (22). The excursion of the potentiation factor was quantified using a ratio between mean values at times 160-180 and 0-20 min, and is called the potentiation factor ratio (PFR). The second component of the model describes the insulin response to the rate of change in glucose concentration. This component is termed rate sensitivity, which is related to early insulin release. The model parameters were estimated from glucose and C-peptide concentration by regularized least squares, as described previously. Regularization involves the choice of 
smoothing factors that were selected to obtain glucose and C-peptide model residuals with standard deviations close to the expected measurement error ( $1 \%$ for glucose and $5 \%$ for C-peptide). ISR were calculated from the model every $5 \mathrm{~min}$. Estimation of the individual model parameters was performed blinded to the randomization of patients to treatment.

In addition to model-derived parameters, we also calculated the insulinogenic index, a marker of early insulin release, as follows: insulin $_{\mathrm{T}=30}-$ insulin $_{\mathrm{T}=0}$ )/ (glucose $_{\mathrm{T}=30}-$ glucose $_{\mathrm{T}=0}$ ).

\section{Statistical analyses}

The primary endpoint of the study, on which the power analysis was based, was change from baseline in postprandial incremental AUC for triglycerides at week 16, and was reported before (17). Postprandial glucose, insulin, and C-peptide concentrations were secondary objectives. Modeling analysis of $\beta$-cell function was an exploratory endpoint of the original study protocol. The statistical analyses were conducted using an analysis of covariance (ANCOVA) model. Change from baseline in $\beta$-cell parameters (glucose sensitivity, fasting ISR, rate sensitivity, PFR) and other parameters of interest was used as the response variable, treatment as fixed effect, and the respective baseline values as a covariate in addition to age at baseline and treatment-induced changes in bodyweight. Parameters that were non-normally distributed were log-transformed. Comparisons between each pair of treatment arms were obtained using contrasts and a twosided 0.05 significance level. No multiplicity adjustments were used. Data are presented as mean values \pm s.E.M. or median \pm IQR. All statistical analyses were run on SPSS for Mac version 19.0 (SPSS).

\section{Results}

\section{Baseline characteristics}

Table 1 lists the characteristics in the three treatment groups at baseline as previously published (17). The entire study population was Caucasian and $70 \%$ were male. No differences in demographic characteristics, medical history, or use of concomitant medications (Supplementary Table 1 , see section on supplementary data given at the end of this article) were observed among the treatment groups at baseline (17). Importantly, there were no differences between the use of insulin secretagogues at baseline (Table 1). Overall, diabetes was well controlled;
Table 1 Baseline characteristics in the treatment group. Data are presented as mean \pm S.E.M.

\begin{tabular}{|c|c|c|c|}
\hline & PBO & ALO & ALO/PIO \\
\hline$n$ & 24 & 25 & 22 \\
\hline Sex (\% men) & 83 & 60 & 68 \\
\hline Age (years) & $59.1 \pm 6.2$ & $58.7 \pm 6.5$ & $59.1 \pm 6.9$ \\
\hline Weight (kg) & $99(93-111)$ & $99(85-102)$ & $93(86-103)$ \\
\hline BMI $\left(\mathrm{kg} / \mathrm{m}^{2}\right)$ & $32.1 \pm 4.0$ & $31.1 \pm 4.2$ & $31.2 \pm 3.5$ \\
\hline Systolic blood pressure $(\mathrm{mmHg})$ & $141 \pm 2$ & $140 \pm 3$ & $139 \pm 4$ \\
\hline Diastolic blood pressure $(\mathrm{mmHg})$ & $86 \pm 1$ & $83 \pm 2$ & $83 \pm 2$ \\
\hline Diabetes duration (years) & $5.5 \pm 3.2$ & $6.4 \pm 3.6$ & $5.0 \pm 3.8$ \\
\hline $\mathrm{A} 1 \mathrm{C}(\%)$ & $6.6 \pm 0.7$ & $6.8 \pm 0.8$ & $6.6 \pm 0.6$ \\
\hline Fasting glucose $(\mathrm{mmol} / \mathrm{l})$ & $8.9 \pm 1.6$ & $9.3 \pm 2.8$ & $8.5 \pm 2.0$ \\
\hline Anti-hyperglycemic agent $(n, \%)$ & $23(96)$ & $22(88)$ & $21(95)$ \\
\hline Use of metformin $(n, \%)$ & $13(57)$ & $13(60)$ & $12(57)$ \\
\hline Use of sulfonylurea $(n, \%)$ & $6(26)$ & $6(28)$ & $8(38)$ \\
\hline Use of glinidines $(n, \%)$ & $4(17)$ & $3(12)$ & $1(5)$ \\
\hline
\end{tabular}

ALO, alogliptin; PBO, placebo; PIO, pioglitazone.

however, A1C was just above target as recommended by the ADA/EASD guidelines for patients with uncomplicated T2DM of relatively short duration and in the absence of significant co-morbidity (4). At 16 weeks, ALO/PIO increased, while ALO monotherapy reduced weight from baseline (Table 2).

\section{Parameters of glycemic control}

As reported in our previous study, following 16 weeks of treatment, both ALO/PIO and ALO significantly reduced $\mathrm{A} 1 \mathrm{C}$ from baseline, as compared with $\mathrm{PBO}$ $(P<0.001)$ (Table 2 and Fig. $2 A)$. Similarly, fasting glucose concentrations were reduced by both ALO/PIO and ALO treatment (Table 2 and Fig. 2B). Both parameters were reduced by ALO/PIO combination therapy to a greater extent than ALO monotherapy (Table 2 and Fig. 2A and B). As compared with baseline, fasting glucose levels increased in the PBO group at week 16 (Table 2 and Fig. 2B).

\section{Postprandial measures}

Both ALO/PIO combination therapy and ALO monotherapy decreased postprandial glucose concentrations as compared with PBO (Table 2 and Fig. 2C, D and E). The surplus reduction in postprandial glucose concentrations by ALO/PIO over ALO monotherapy was significant. Postprandial glucose levels increased in the $\mathrm{PBO}$ group as compared with baseline (Table 2 and Fig. 2C, D and E). ALO/PIO combination therapy reduced postprandial insulin and C-peptide concentration, while ALO vs $\mathrm{PBO}$ did not affect postprandial insulin and C-peptide concentrations (Table 2). Postprandial levels of GLP1 were significantly enhanced in patients with ALO/PIO 
Table 2 Anthropometric and metabolic parameters at baseline and at week 16 of treatment with alogliptin/pioglitazone combination therapy, alogliptin monotherapy, or placebo. Mean \pm s.E.M. or median (IQR).

\begin{tabular}{|c|c|c|c|c|c|c|}
\hline & Week 0 & Week 16 & $\begin{array}{l}\text { Change from } \\
\text { baseline }\end{array}$ & PBO vs ALO & PBO vs ALO/PIO & ALO vs ALO/PIO \\
\hline \multicolumn{7}{|c|}{ Weight (kg) } \\
\hline PBO & 99 (93 to 111$)$ & 100 (94 to 112 ) & $0.6(-0.2$ to 1.3$)$ & 0.06 & 0.427 & 0.008 \\
\hline ALO & 99 (85 to 102$)$ & 95 (84 to 102$)$ & $-0.1(-1.8$ to 1.5$)$ & & & \\
\hline ALO/PIO & 93 (86 to 103$)$ & 95 (89 to 101$)$ & $1.4(-0.2$ to 2.5$)$ & & & \\
\hline \multicolumn{7}{|l|}{$\mathrm{A} 1 \mathrm{C}(\%)$} \\
\hline PBO & $6.6 \pm 0.1$ & $7.0 \pm 0.2$ & $0.4 \pm 0.1$ & $<0.001$ & $<0.001$ & $<0.001$ \\
\hline ALO & $6.8 \pm 0.2$ & $6.4 \pm 0.2$ & $-0.4 \pm 0.2$ & & & \\
\hline ALO/PIO & $6.6 \pm 0.1$ & $5.7 \pm 0.1$ & $-0.9 \pm 0.1$ & & & \\
\hline \multicolumn{7}{|c|}{ FPG (mmol/l) } \\
\hline PBO & $8.9 \pm 0.3$ & $9.6 \pm 0.4$ & $0.7 \pm 0.3$ & 0.008 & $<0.001$ & 0.001 \\
\hline ALO & $9.3 \pm 0.6$ & $8.2 \pm 0.5$ & $-1.2 \pm 0.6$ & & & \\
\hline ALO/PIO & $8.5 \pm 0.4$ & $6.6 \pm 0.3$ & $-1.9 \pm 0.4$ & & & \\
\hline \multicolumn{7}{|c|}{ FPI (pmol/l) } \\
\hline PBO & $130 \pm 12$ & $128 \pm 12$ & $-2 \pm 7$ & 0.515 & 0.001 & $<0.001$ \\
\hline ALO & $118 \pm 11$ & $121 \pm 11$ & $3 \pm 7$ & & & \\
\hline ALO/PIO & $114 \pm 15$ & $89 \pm 8$ & $-25 \pm 11$ & & & \\
\hline \multicolumn{7}{|c|}{ HOMA-S (\%) } \\
\hline PBO & $37 \pm 3$ & $37 \pm 3$ & $0 \pm 2$ & 0.473 & $<0.001$ & $<0.001$ \\
\hline ALO & $42 \pm 4$ & $37 \pm 3$ & $-3 \pm 3$ & & & \\
\hline ALO/PIO & $46 \pm 5$ & $57 \pm 4$ & $10 \pm 4$ & & & \\
\hline \multicolumn{7}{|c|}{$A_{U} C_{\text {glucose }}(\mathrm{mmol} / \mathrm{l} \mathrm{h})$} \\
\hline PBO & $75 \pm 3$ & $81 \pm 4$ & $6 \pm 2$ & 0.008 & $<0.001$ & $<0.001$ \\
\hline ALO & $81 \pm 5$ & $69 \pm 5$ & $-12 \pm 6$ & & & \\
\hline ALO/PIO & $79 \pm 5$ & $57 \pm 4$ & $-22 \pm 4$ & & & \\
\hline \multicolumn{7}{|c|}{$A \cup C_{\text {insulin }}(\mathrm{pmol} / \mathrm{l} \mathrm{h})$} \\
\hline PBO & $2846 \pm 320$ & $2879 \pm 354$ & $33 \pm 149$ & 0.310 & $<0.001$ & 0.002 \\
\hline ALO & $2595 \pm 251$ & $2274 \pm 269$ & $-321 \pm 150$ & & & \\
\hline ALO/PIO & $2747 \pm 317$ & $1925 \pm 211$ & $-822 \pm 206$ & & & \\
\hline \multicolumn{7}{|c|}{$\mathrm{AUC}_{\mathrm{C} \text {-peptide }}(\mathrm{nmol} / \mathrm{l} \mathrm{h})$} \\
\hline PBO & $16.5 \pm 1.2$ & $18.7 \pm 1.6$ & $2.3 \pm 0.9$ & 0.085 & 0.003 & 0.198 \\
\hline ALO & $17.3 \pm 1.2$ & $16.2 \pm 1.2$ & $-1.1 \pm 0.7$ & & & \\
\hline ALO/PIO & $17.4 \pm 1.4$ & $15.8 \pm 1.5$ & $-1.5 \pm 1.2$ & & & \\
\hline \multicolumn{7}{|c|}{$A \cup C_{\text {glucagon }}(\mu \mathrm{g} / \mathrm{l} \mathrm{h})$} \\
\hline PBO & $30.9 \pm 2.6$ & $32.3 \pm 2.0$ & $1.4 \pm 1.5$ & $<0.001$ & $<0.001$ & 0.674 \\
\hline ALO & $28.9 \pm 2.1$ & $23.2 \pm 1.9$ & $-5.7 \pm 1.6$ & & & \\
\hline ALO/PIO & $32.7 \pm 2.7$ & $25.5 \pm 2.0$ & $-7.2 \pm 1.7$ & & & \\
\hline \multicolumn{7}{|c|}{$\mathrm{AUC}_{\mathrm{GLP} 1 \text { active }}(\mathrm{pmol} / \mathrm{l} \mathrm{h})$} \\
\hline PBO & $1365 \pm 232$ & $1231 \pm 236$ & $-133 \pm 127$ & $<0.001$ & 0.009 & 0.081 \\
\hline ALO & $1553 \pm 254$ & $4954 \pm 840$ & $3401 \pm 739$ & & & \\
\hline ALO/PIO & $1070 \pm 152$ & $3035 \pm 416$ & $1965 \pm 359$ & & & \\
\hline \multicolumn{7}{|c|}{ OGIS $\left(\mathrm{ml} / \mathrm{min}\right.$ per $\left.\mathrm{m}^{2}\right)$} \\
\hline PBO & $228 \pm 8$ & $214 \pm 7$ & $-14 \pm 6$ & 0.04 & $<0.001$ & $<0.001$ \\
\hline ALO & $229 \pm 10$ & $249 \pm 1$ & $20 \pm 13$ & & & \\
\hline ALO/PIO & $241 \pm 12$ & $306 \pm 13$ & $63 \pm 15$ & & & \\
\hline
\end{tabular}

AUC, area under the curve; FPG, fasting plasma glucose; FPI, fasting plasma insulin; OGIS, oral glucose insulin sensitivity.

as compared with $\mathrm{PBO}$, with the largest increase in the ALO monotherapy arm (17). Postprandial glucagon levels were suppressed to a similar extent by ALO/PIO and ALO monotherapy, as shown previously (17) (Table 2).

\section{$\beta$-cell function parameters}

Fasting insulin secretion at a fixed glucose level was significantly improved by $35 \pm 19 \%$ for combined
ALO/PIO treatment, but not for ALO monotherapy (Fig. 3). Combined ALO/PIO treatment also improved $\beta$-cell glucose sensitivity by $58 \pm 18 \%$. Insulinogenic index and rate sensitivity as measures for early insulin secretion were not affected by any of the treatment arms. Baseline and week 16 values for the insulinogenic index were: 168 (60-206) and 115 (71-246) respectively for ALO/PIO; 122 (76-204) and 133 (72-240) respectively for ALO; and 166 (123-238) and 167 (106-243) respectively for PBO 
A

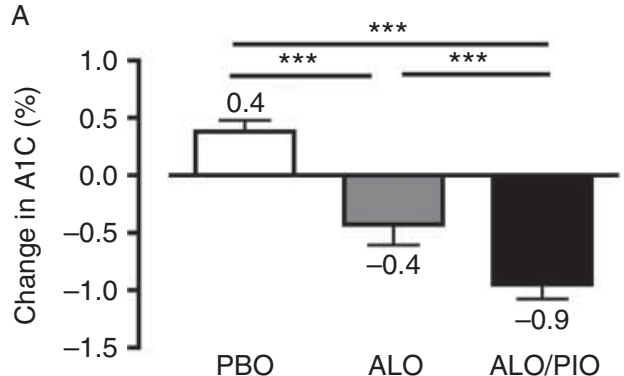

C

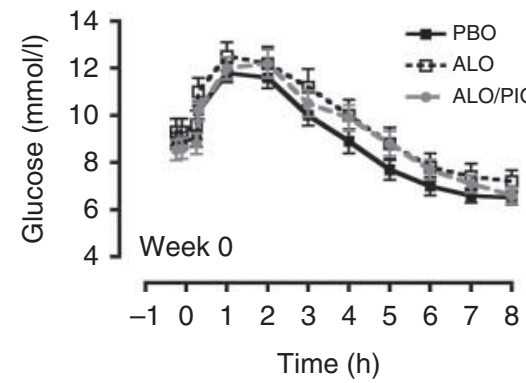

D
B
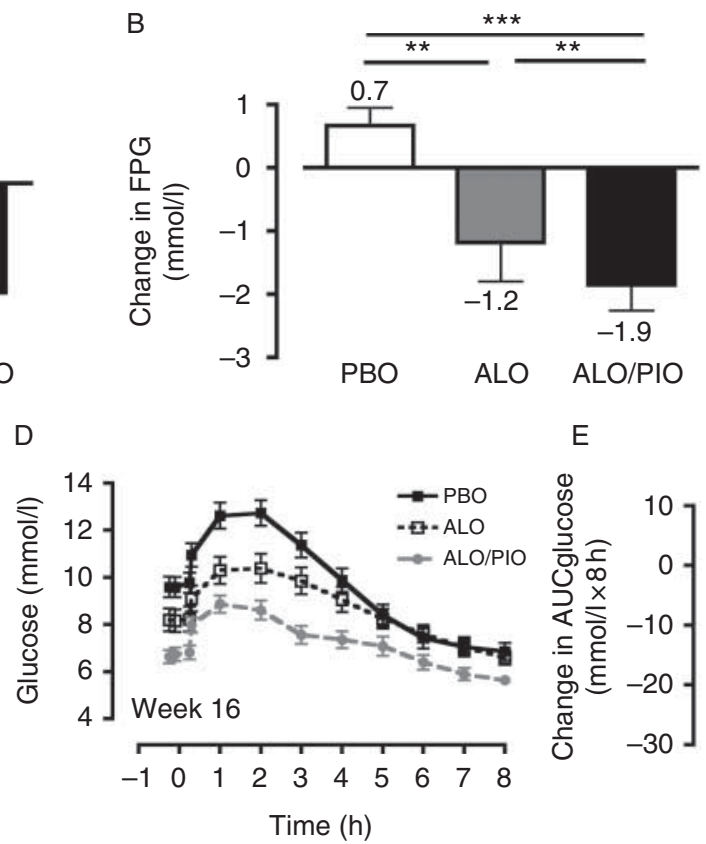

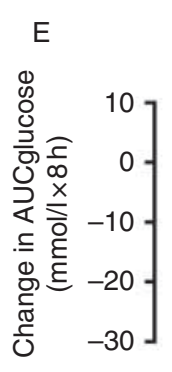

6.7

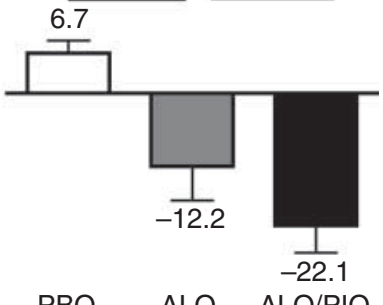

\section{Figure 2}

Changes in parameters of glucose metabolism after treatment with alogliptin/pioglitazone (ALO/PIO) combination therapy, ALO monotherapy, or placebo (PBO) treatment for 16 weeks. $A 1 C(A)$ and fasting glucose concentrations (B) were reduced by ALO/PIO combination therapy to a greater extent than ALO

$(P=$ NS $)$. Changes in rate sensitivity were also nonsignificant as shown in Fig. 3. PFR was not affected by study medication (Fig. 3; Supplementary Table 2 and Figure 1, see section on supplementary data given at the end of this article).

\section{Insulin sensitivity}

Fasting insulin sensitivity, defined as HOMA-IR, was significantly increased by ALO/PIO combination therapy as compared with both $\mathrm{PBO}$ and ALO, but was not altered by ALO monotherapy (Table 2). However, both ALO/PIO and ALO, relative to $\mathrm{PBO}$, improved postprandial insulin sensitivity (OGIS) (Table 2). As expected, ALO/PIO resulted in a significantly greater improvement in OGIS as compared with ALO monotherapy (Table 2).

\section{Safety and tolerability}

One person withdrew informed consent and left the study, this was not driven by an adverse event (AE; Fig. 1). The incidence of AEs: 59\% for the ALO/PIO group, 63\% for monotherapy as compared with PBO. Similarly, postprandial glucose levels were lower following ALO/PIO combination therapy then ALO monotherapy as compared with PBO (C, D and E). **P<0.01; ***P<0.001.

the PBO group, and $76 \%$ for the ALO group has been reported previously (17). The most common AEs by preferred term were nasopharyngitis, constipation, and dizziness. Mild hypoglycemia was reported by three individuals in the ALO/PIO arm, but none in other groups. Most AEs were mild in severity and assessed as related to study treatment. Five severe AEs were reported in three subjects, none resulting in discontinuation from the study, and no deaths occurred during the course of the study. Of the five severe AEs, three were reported for one subject in the ALO/PIO group as a result of an incident (fall, head injury, and concussion), which were considered by the investigator not to be related to study drug. The other severe AEs were gastric ulcer and nephrolithiasis, reported for one subject each in the ALO group. Both were assessed as related to study drug. No clinically relevant changes in laboratory tests, ECGs, or physical examination findings were observed. ALO was generally safe and well tolerated in this study as monotherapy and as coadministered with PIO. The incidence of AEs and severe AEs was low and consistent with previous studies (17). 
A

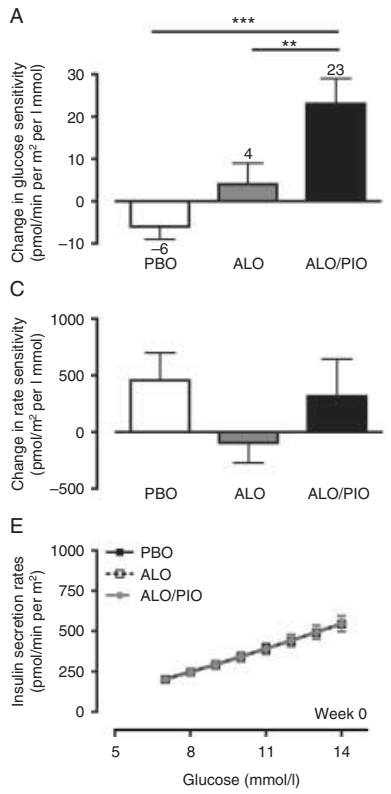

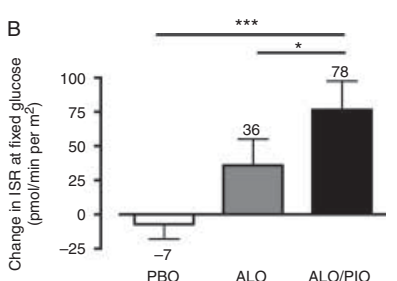
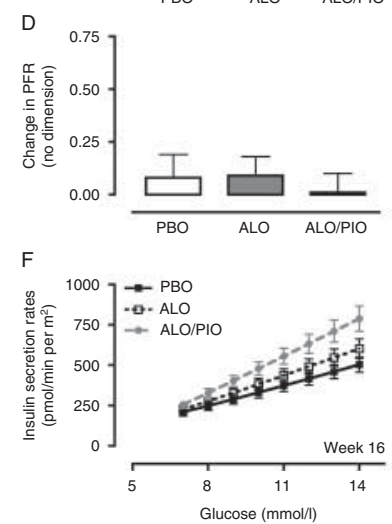

\section{Figure 3}

Changes in model-derived $\beta$-cell function parameters after treatment with alogliptin/pioglitazone (ALO/PIO) combination therapy, ALO monotherapy, or placebo (PBO) treatment for 16 weeks. Glucose sensitivity (A, E and $F$ ) and insulin secretion rate (ISR) at $8 \mathrm{mmol} / /$ glucose (B, E and F) were improved by ALO/PIO combination therapy, but not by ALO monotherapy. Rate sensitivity and potentiation factor ratio (PFR) were not altered by any treatment $(C$ and $D) .{ }^{*} P<0.05 ; * * P<0.01 ; * * * P<0.001$.

\section{Discussion}

In this study, we demonstrate for the first time that initial combination therapy with ALO/PIO in patients with uncomplicated T2DM just above glycemic targets on a single oral anti-hyperglycemic agent improves islet-cell function as compared with ALO monotherapy and PBO. Together with beneficial changes in insulin sensitivity, ALO/PIO combination therapy improved glycemic control to a greater extent than ALO monotherapy and PBO, as has been also reported more recently (17). Importantly, combined intervention with ALO/PIO therapy was well tolerated.

ALO/PIO combination therapy addressed multiple core defects of T2DM by its complimentary mode of action. First, ALO/PIO combination therapy improved $\beta$-cell function. Using modeling analysis of glucose and C-peptide concentrations following a standardized meal test, we observed improvement in glucose sensitivity of the $\beta$-cell and increased fasting ISR by ALO/PIO treatment,

both compared with ALO monotherapy and PBO, indicating improved $\beta$-cell function. This improvement in $\beta$-cell function is likely a combined effect of both ALO and PIO. DPP4 inhibitors were extensively shown to enhance static and dynamic $\beta$-cell measures, the latter including the insulinogenic index, mathematical model-derived parameters $\beta$-cell glucose sensitivity and fasting insulin secretion, and hyperglycemic clamp-measured first-phase, second-phase, and arginine-induced insulin secretion $(8,23)$. PIO was also shown to improve model-derived parameters of $\beta$-cell function in subjects with T2DM (24) and in patients at high risk to develop T2DM (25). However, whether these improvements are direct effects of TZD at the level of the $\beta$-cell, as suggested by in vitro studies (26), or secondary to changes in insulin sensitivity and glucose levels, remains uncertain.

Secondly, in addition to changes in $\beta$-cell function, ALO/PIO treatment improved $\alpha$-cell function as well. ALO/PIO treatment resulted in reduced glucagon levels, which contribute to improved glycemic control by reducing hepatic glucose production (27). However, it should be noted that insulin levels were reduced by $\mathrm{ALO} / \mathrm{PIO}$ treatment as well, therefore making the net effect on hepatic glucose production in this study uncertain. Lowering of postprandial glucagon levels has been extensively shown following short-term and longterm treatment with DPP4 inhibitors (8), which may be attributed to increased GLP1 levels (28). Indeed, active GLP1 levels were significantly increased by treatment with ALO/PIO as was reported elsewhere (17).

Thirdly, in addition to the beneficial effects of $\mathrm{ALO} / \mathrm{PIO}$ on islet-cell function and incretin levels, combined ALO/PIO treatment improved measures of fasting (HOMA-IR) and postprandial (OGIS) insulin sensitivity. PIO is well known to increase both hepatic and skeletal muscle insulin sensitivity (11). Moreover, PIO improves adipose tissue function by stimulating adequate production of adipocytokines such as adiponectin and leptin, and also stimulates fatty acid uptake, thus protecting non-adipose tissue from lipid overload (29). ALO treatment on the other hand is usually not associated with improvements in peripheral insulin sensitivity, although by reducing glucagon levels, hepatic glucose production may be reduced during hyperinsulinemia. In our study, improved insulin sensitivity contributed to the reduction in A1C levels by ALO/PIO treatment, since both fasting and post-meal glucose levels were reduced in the presence of declined fasting and postprandial insulin levels respectively. 
Interestingly, ALO/PIO improved these aspects in patients with uncomplicated T2DM, with glucose levels just above glycemic targets as recently issued by the ADA/EASD guidelines (4), leading to an impressive $0.9 \%$ reduction in A1C. Greater reductions in A1C levels up to $1.5 \%$ were demonstrated with DPP4 inhibitor/TZD combination therapy in T2DM patients with A1C levels of $8-9 \%$ at baseline $(14,15)$. Similarly as observed in our study, in those trials hypoglycemia rates were comparable to PBO. This may be attributed to the fact that insulin secretion by ALO and PIO is related to prevailing glucose levels, and as such, no inappropriate insulin secretion occurs.

Another advantage of combination therapy with multiple hypoglycemic agents with complementary mechanisms of action is that side effects may be minimized, since lower dosages of each drug can be administered $(7,30)$. For PIO, there are long-term safety concerns due to reports of increased risk to develop bladder cancer (31) and bone fractures (32), in addition to their well-known fluid-retaining effects. These side effects are mostly related to higher dosages, while, importantly, anti-hyperglycemic effects are retained at lower dosages. As TZDs were durably shown to improve glycemic control (1) by preventing further decline in $\beta$-cell function (33) and PIO is not associated with increased risk for cardiovascular disease $(34,35)$, PIO is an attractive glucose-lowering compound.

The effects of ALO monotherapy in our study were relatively modest. ALO monotherapy increased GLP1 concentrations, reduced glucagon concentrations, and improved insulin sensitivity, which may have been due to reduction in hepatic glucose production due to suppression of glucagon levels. Unfortunately, we did not use tracer methodology to test the effects of ALO on hepatic glucose production. Interestingly, in spite of the greatest increase in GLP1 after ALO monotherapy, these changes did not translate into better $\beta$-cell function or increased C-peptide secretion. An explanation could be that our patients displayed only modest hyperglycemia, and DPP4 inhibitors are well known to work in a glucosedependent mechanism.

Limitations of our study include the relatively small size of the study, adequate glycemic control at baseline, and lack of a PIO monotherapy arm. However, our sample size proved to be sufficient to detect the observed A1C changes. Also, although the overall glycemic control at baseline was good, both drugs were able to further lower A1C levels. Moreover, the effects of PIO monotherapy on glycemic variables (and the additional value of adding a DPP4 inhibitor to PIO monotherapy on these measures) have been extensively studied and published $(11,14)$.

Finally, we chose to study $\beta$-cell function by performing standardized meal tests combined with mathematical modeling of $\beta$-cell function parameters. In general, the hyperglycemic clamp is currently considered to be the gold standard for the quantification of insulin secretion; however, it may not represent a physiological test because it does not include the effects of gut-derived factors, including incretin hormones and neuronal signals on $\beta$-cell function. A potential disadvantage of the meal test as compared with an oral glucose tolerance test (OGTT) could be more variable absorption of nutrients including glucose, resulting in a nonstandardized secretion stimulus to the $\beta$-cells. Also, variability exists between studies due to differences in meal composition, potentially hampering comparisons. On the other hand, a previous study did not show differences in variability in $\beta$-cell function parameters following a meal test vs an OGTT in a population-based cohort (36).

In conclusion, ALO/PIO combination therapy improved fasting and postprandial glucose levels by addressing partly overlapping and complementary core defects of T2DM, and was well tolerated. Ongoing and future studies need to demonstrate potential benefits of early aggressive combination therapy as compared with the currently advocated stepwise treatment protocol.

\section{Supplementary data}

This is linked to the online version of the paper at http://dx.doi.org/10.1530/ EJE-13-0639.

Declaration of interest

C Wilson and P Fleck are employed by Takeda. B Eliasson and U Smith have received speakers' fees from Takeda. M R Taskinen is a shareholder, and has received research grants from Eli Lilly, MSD, and Takeda and honoraria from Novartis and Boehringer Mannheim, and speakers' fees.

\section{Funding}

Takeda Global Research and Development sponsored this study. Sponsors were involved in the study design, protocol development, and the collection, review, and analysis of data.

\section{Author contribution statement}

Study design by B Eliasson, C Wilson, P Fleck, M R Taskinen, U Smith, and $M$ Diamant. Data collection by $B$ Eliasson and D L Möller-Goede. Data analysis by D H Van Raalte, R E van Genugten, B Eliasson, A Mari, and A Tura. Manuscript preparation by D H Van Raalte, R E van Genugten, B Eliasson, A Mari, C Wilson, P Fleck, M R Taskinen, U Smith, and M Diamant. 


\section{Acknowledgements}

Prof. Dr M Diamant is guarantor of this work.

\section{References}

1 Defronzo RA. Banting Lecture. From the triumvirate to the ominous octet: a new paradigm for the treatment of type 2 diabetes mellitus. Diabetes 200958 773-795. (doi:10.2337/db09-9028)

2 Weyer C, Bogardus C, Mott DM \& Pratley RE. The natural history of insulin secretory dysfunction and insulin resistance in the pathogenesis of type 2 diabetes mellitus. Journal of Clinical Investigation 1999104 787-794. (doi:10.1172/JCI7231)

3 Saydah SH, Fradkin J \& Cowie CC. Poor control of risk factors for vascular disease among adults with previously diagnosed diabetes. Journal of the American Medical Association 2004291 335-342. (doi:10.1001/jama.291.3.335)

4 Inzucchi SE, Bergenstal RM, Buse JB, Diamant M, Ferrannini E, Nauck M, Peters AL, Tsapas A, Wender R \& Matthews DR. Management of hyperglycaemia in type 2 diabetes: a patient-centered approach. Position statement of the American Diabetes Association (ADA) and the European Association for the Study of Diabetes (EASD). Diabetologia 201255 1577-1596. (doi:10.1007/s00125-012-2534-0)

5 Zinman B. Initial combination therapy for type 2 diabetes mellitus: is it ready for prime time? American Journal of Medicine 2011124 S19-S34. (doi:10.1016/j.amjmed.2010.11.003)

6 Esposito K, Bellastella G \& Giugliano D. When metformin fails in type 2 diabetes mellitus. Archives of Internal Medicine 2011171 365-366. (doi:10.1001/archinternmed.2011.4)

7 Zinman B, Harris SB, Neuman J, Gerstein HC, Retnakaran RR, Raboud J, Qi Y \& Hanley AJ. Low-dose combination therapy with rosiglitazone and metformin to prevent type 2 diabetes mellitus (CANOE trial): a double-blind randomised controlled study. Lancet 2010376 103-111. (doi:10.1016/S0140-6736(10)60746-5)

8 van Genugten RE, van Raalte DH \& Diamant M. Dipeptidyl peptidase-4 inhibitors and preservation of pancreatic islet-cell function: a critical appraisal of the evidence. Diabetes, Obesity and Metabolism 201214 101-111. (doi:10.1111/j.1463-1326.2011.01473.x)

9 van Genugten RE, van Raalte DH \& Diamant M. Does glucagon-like peptide-1 receptor agonist therapy add value in the treatment of type 2 diabetes? Focus on exenatide. Diabetes Research and Clinical Practice 200986 (Suppl 1) S26-S34. (doi:10.1016/S0168-8227(09)70006-3)

10 van Genugten RE, Moller-Goede DL, van Raalte DH \& Diamant M. Extra-pancreatic effects of incretin-based therapies: potential benefit for cardiovascular-risk management in type 2 diabetes. Diabetes, Obesity \& Metabolism 201315 593-606. (doi:10.1111/dom.12050)

11 Campbell IW \& Mariz S. $\beta$-cell preservation with thiazolidinediones. Diabetes Research and Clinical Practice 200776 163-176. (doi:10.1016/ j.diabres.2006.08.015)

12 Garber AJ, Schweizer A, Baron MA, Rochotte E \& Dejager S. Vildagliptin in combination with pioglitazone improves glycaemic control in patients with type 2 diabetes failing thiazolidinedione monotherapy: a randomized, placebo-controlled study. Diabetes, Obesity and Metabolism 20079 166-174. (doi:10.1111/j.1463-1326.2006.00684.x)

13 Rosenstock J, Brazg R, Andryuk PJ, Lu K, Stein P \& Sitagliptin Study G. Efficacy and safety of the dipeptidyl peptidase- 4 inhibitor sitagliptin added to ongoing pioglitazone therapy in patients with type 2 diabetes: a 24-week, multicenter, randomized, double-blind, placebo-controlled, parallel-group study. Clinical Therapeutics 200628 1556-1568. (doi:10.1016/j.clinthera.2006.10.007)

14 DeFronzo RA, Burant CF, Fleck P, Wilson C, Mekki Q \& Pratley RE. Efficacy and tolerability of the DPP-4 inhibitor alogliptin combined with pioglitazone, in metformin-treated patients with type 2 diabetes. Journal of Clinical Endocrinology and Metabolism 201297 1615-1622. (doi:10.1210/jc.2011-2243)
15 Rosenstock J, Kim SW, Baron MA, Camisasca RP, Cressier F, Couturier A $\&$ Dejager S. Efficacy and tolerability of initial combination therapy with vildagliptin and pioglitazone compared with component monotherapy in patients with type 2 diabetes. Diabetes, Obesity and Metabolism 20079 175-185. (doi:10.1111/j.1463-1326.2006.00698.x)

16 Triplitt C, Cersosimo E \& DeFronzo RA. Pioglitazone and alogliptin combination therapy in type 2 diabetes: a pathophysiologically sound treatment. Vascular Health and Risk Management 20106 671-690.

17 Eliasson B, Moller-Goede D, Eeg-Olofsson K, Wilson C, Cederholm J, Fleck P, Diamant M, Taskinen MR \& Smith U. Lowering of postprandial lipids in individuals with type 2 diabetes treated with alogliptin and/or pioglitazone: a randomised double-blind placebo-controlled study. Diabetologia 201255 915-925. (doi:10.1007/s00125-011-2447-3)

18 Levy JC, Matthews DR \& Hermans MP. Correct homeostasis model assessment (HOMA) evaluation uses the computer program. Diabetes Care 199821 2191-2192. (doi:10.2337/diacare.21.12.2191)

19 Mari A, Pacini G, Murphy E, Ludvik B \& Nolan JJ. A model-based method for assessing insulin sensitivity from the oral glucose tolerance test. Diabetes Care 200124 539-548. (doi:10.2337/diacare.24.3.539)

20 Mari A, Schmitz O, Gastaldelli A, Oestergaard T, Nyholm B \& Ferrannini E. Meal and oral glucose tests for assessment of $\beta$-cell function: modeling analysis in normal subjects. American Journal of Physiology. Endocrinology and Metabolism 2002283 E1159-E1166.

21 Mari A, Tura A, Gastaldelli A \& Ferrannini E. Assessing insulin secretion by modeling in multiple-meal tests: role of potentiation. Diabetes 2002 51 (Suppl 1) S221-S226. (doi:10.2337/diabetes.51.2007.S221)

22 Mari A \& Ferrannini E. $\beta$-cell function assessment from modelling of oral tests: an effective approach. Diabetes, Obesity and Metabolism 200810 (Suppl 4) 77-87. (doi:10.1111/j.1463-1326.2008.00946.x)

23 Foley JE, Bunck MC, Moller-Goede DL, Poelma M, Nijpels G, Eekhoff EM, Schweizer A, Heine RJ \& Diamant M. $\beta$ cell function following 1 year vildagliptin or placebo treatment and after 12 week washout in drug-naive patients with type 2 diabetes and mild hyperglycaemia: a randomised controlled trial. Diabetologia 201154 1985-1991. (doi:10.1007/s00125-011-2167-8)

24 Gastaldelli A, Ferrannini E, Miyazaki Y, Matsuda M, Mari A \& DeFronzo RA. Thiazolidinediones improve $\beta$-cell function in type 2 diabetic patients. American Journal of Physiology. Endocrinology and Metabolism 2007292 E871-E883. (doi:10.1152/ajpendo.00551.2006)

25 Xiang AH, Peters RK, Kjos SL, Marroquin A, Goico J, Ochoa C, Kawakubo M \& Buchanan TA. Effect of pioglitazone on pancreatic $\beta$-cell function and diabetes risk in Hispanic women with prior gestational diabetes. Diabetes 200655 517-522. (doi:10.2337/diabetes.55.02.06. db05-1066)

26 Vandewalle B, Moerman E, Lefebvre B, Defrance F, Gmyr V, Lukowiak B, Kerr Conte J \& Pattou F. PPAR $\gamma$-dependent and -independent effects of rosiglitazone on lipotoxic human pancreatic islets. Biochemical and Biophysical Research Communications 2008366 1096-1101. (doi:10.1016/j.bbrc.2007.12.088)

27 Shah P, Vella A, Basu A, Basu R, Schwenk WF \& Rizza RA. Lack of suppression of glucagon contributes to postprandial hyperglycemia in subjects with type 2 diabetes mellitus. Journal of Clinical Endocrinology and Metabolism 200085 4053-4059.

28 Nauck MA, Kleine N, Orskov C, Holst JJ, Willms B \& Creutzfeldt W. Normalization of fasting hyperglycaemia by exogenous glucagon-like peptide 1 (7-36 amide) in type 2 (non-insulin-dependent) diabetic patients. Diabetologia 199336 741-744. (doi:10.1007/BF00401145)

29 Kintscher U \& Law RE. PPAR $\gamma$-mediated insulin sensitization: the importance of fat versus muscle. American Journal of Physiology. Endocrinology and Metabolism 2005288 E287-E291. (doi:10.1152/ ajpendo.00440.2004)

30 Weissman P, Goldstein BJ, Rosenstock J, Waterhouse B, Cobitz AR, Wooddell MJ \& Strow LJ. Effects of rosiglitazone added to submaximal doses of metformin compared with dose escalation of metformin in type 2 diabetes: the EMPIRE Study. Current Medical Research and Opinion 200521 2029-2035. (doi:10.1185/030079905X74844) 
31 Lewis JD, Ferrara A, Peng T, Hedderson M, Bilker WB, Quesenberry CP Jr, Vaughn DJ, Nessel L, Selby J \& Strom BL. Risk of bladder cancer among diabetic patients treated with pioglitazone: interim report of a longitudinal cohort study. Diabetes Care 201134 916-922. (doi:10.2337/dc10-1068)

32 Kahn SE, Zinman B, Lachin JM, Haffner SM, Herman WH, Holman RR, Kravitz BG, Yu D, Heise MA, Aftring RP et al. Rosiglitazone-associated fractures in type 2 diabetes: an Analysis from A Diabetes Outcome Progression Trial (ADOPT). Diabetes Care 200831 845-851. (doi:10.2337/dc07-2270)

33 Kahn SE, Lachin JM, Zinman B, Haffner SM, Aftring RP, Paul G, Kravitz BG, Herman WH, Viberti G, Holman RR et al. Effects of rosiglitazone, glyburide, and metformin on $\beta$-cell function and insulin sensitivity in ADOPT. Diabetes 201160 1552-1560. (doi:10.2337/ db10-1392)
34 Consoli A \& Formoso G. Do thiazolidinediones still have a role in treatment of type 2 diabetes mellitus? Diabetes, Obesity and Metabolism 201315 967-77. (doi:10.1111/dom.12101)

35 Dormandy JA, Charbonnel B, Eckland DJ, Erdmann E, Massi-Benedetti M, Moules IK, Skene AM, Tan MH, Lefebvre PJ, Murray GD et al. Secondary prevention of macrovascular events in patients with type 2 diabetes in the PROactive Study (PROspective pioglitAzone Clinical Trial In macroVascular Events): a randomised controlled trial. Lancet 2005366 1279-1289. (doi:10.1016/ S0140-6736(05)67528-9)

36 Rijkelijkhuizen JM, Girman CJ, Mari A, Alssema M, Rhodes T, Nijpels G, Kostense PJ, Stein PP, Eekhoff EM, Heine RJ et al. Classical and modelbased estimates of $\beta$-cell function during a mixed meal vs an OGTT in a population-based cohort. Diabetes Research and Clinical Practice 200983 280-288. (doi:10.1016/j.diabres.2008.11.017)

Received 2 August 2013

Revised version received 13 November 2013

Accepted 13 January 2014 